- Original Article-

\title{
Oral Administration of Fermented Probiotics Improves the Condition of Feces in Adult Horses
}

\author{
Saori ISHIZAKA ${ }^{1}$, Akira MATSUDA ${ }^{2}$, Yosuke AMAGAI ${ }^{1}$, Kumiko OIDA $^{1}$, Hyosun JANG ${ }^{1}$, \\ Yuko UEDA ${ }^{4}$, Masaki TAKAI ${ }^{4}$, Akane TANAKA ${ }^{1,3 *}$ and Hiroshi MATSUDA ${ }^{1,2 *}$ \\ ${ }^{1}$ Cooperative Major in Advanced Health Science, Graduate School of Bio-Applications and System Engineering, \\ Tokyo University of Agriculture and Technology, Tokyo 183-8509, Japan \\ ${ }^{2}$ Laboratory of Veterinary Molecular Pathology and Therapeutics, Division of Animal Life Science, Institute of \\ Agriculture, Tokyo University of Agriculture and Technology, Tokyo 183-8509, Japan \\ ${ }^{3}$ Laboratory of Comparative Animal Medicine, Division of Animal Life Science, Institute of Agriculture, Tokyo \\ University of Agriculture and Technology, Tokyo 183-8509, Japan \\ ${ }^{4}$ Miura Co., Ltd., Ehime 799-2696, Japan
}

The effects of probiotics on horses are still controversial. The present study was a randomized, double-blinded, placebo-controlled crossover study designed to evaluate the ability of probiotics to improve intestinal conditions in adult horses. Fermented probiotics were administered to 10 healthy adult geldings for 28 days. The clinical condition of the horses was monitored daily, and the blood and feces were biochemically analyzed every 14 days. In the probiotic-treated group, the concentration of carboxylic acids in the feces was increased at days 14 and 28. In contrast to the fecal $\mathrm{pH}$ in the control group, which increased at days 14 and 28, the fecal $\mathrm{pH}$ in the probiotic-treated group did not increase. Additionally, the relative amounts of enteropathogenic bacterial DNA were diminished in the probiotic-treated group. These results suggest that probiotic bacteria proliferated in the equine intestine. No instances of abnormal clinical conditions or abnormal values in blood tests were observed throughout the study. Oral administration of fermented probiotics may have the ability to improve the intestinal environment biochemically and microbiologically without the risk of adverse effects.

Key words: fecal carboxylic acids, geldings, microbial DNA, probiotics

\author{
J. Equine Sci. \\ Vol. 25, No. 4 \\ pp. $65-72,2014$
}

Probiotics are defined as live microorganisms that confer a health benefit on the host, when administered in adequate amounts [26]. It has been reported that the oral administration of probiotics reduces the risk of gastrointestinal infection and improves the symptoms of acute diarrhea, among numerous other beneficial effects in humans [7, 9]. Invasive pathogenic bacteria produce volatile organic compounds (VOCs) such as phenols, indole, and skatole that cause unpleasant odors in feces [29]. Some probiotic bacteria such as Bacillus subtilis C-3102 and Bifidobacterium

Received: July 14, 2014

Accepted: September 25, 2014

*Corresponding authors: e-mail: hiro@cc.tuat.ac.jp (H. Matsuda), akane@cc.tuat.ac.jp (A. Tanaka)

(C)2014 Japanese Society of Equine Science

This is an open-access article distributed under the terms of the Creative Commons Attribution Non-Commercial No Derivatives (bync-nd) License $<$ http://creativecommons.org/licenses/by-nc-nd/3.0/ . longum BB536 reduced the fecal levels of these compounds in humans and poultry $[21,24,29]$, which indicates the improvement of the gut microenvironment. Lactobacillus acidophilus, Lactobacillus rhamnosus GG, Lactobacillus bulgaricus, and Saccharomyces boulardii are the bacterial species used most frequently as probiotics in humans [28]. Several studies have examined the effects of probiotics on horses. Oral administration of live yeast improves digestion, and oral administration of lactic acid bacteria improves symptoms of enterocolitis in horses $[5,10,13,30]$. However, the administration of probiotics did not prevent diarrhea in horses [15, 22, 34]. Because digestive disease is a common problem, which often requires long-term treatment or even results in death [31], any benefit conferred by probiotics would be of significant value in the equine industry.

In contrast to probiotic bacteria, pathogenic bacteria such as Escherichia coli and Clostridium perfringens are known to cause intestinal diseases in domestic animals 
including horses $[6,11,12,32]$. Miyazaki et al. reported the antibacterial effects of probiotics on pathogenic bacteria [20]. Probiotic supplementation increases lactobacilli proliferation and decreases fecal $\mathrm{pH}[18,27]$. The metabolic byproducts of probiotic bacteria, such as lactic acid and acetic acid, may lower the intestinal $\mathrm{pH}$, which helps inhibit the development of invasive pathogens such as $E$. coli $[20,23]$. Lactobacillus pentosus WE7, an organism of equine origin, has been reported to inhibit the growth of $E$. coli and C. perfringens in vitro [33]. However, the in vivo effect of probiotics on pathogenic bacteria in horses is still unclear. In this study, we showed that oral administration of commercial probiotics improved fecal conditions without inducing adverse effects in adult horses.

\section{Materials and Methods}

\section{Animals}

Ten healthy adult geldings ( 8 Thoroughbreds and 2 Dutch Warmbloods) with a mean age of 14.8 years (range, 5-21 years) and a mean body weight of $548.2 \mathrm{~kg}$ (range, $502-750 \mathrm{~kg}$ ) were used in this study. All horses were housed in individual stalls. Although the exercise programs varied among the horses from day to day, roughly they walked for $30 \mathrm{~min}$, trotted for $30 \mathrm{~min}$ and cantered for $30 \mathrm{~min}$ everyday. Deworming was performed by oral administration of ivermectin (Eqvalan paste; DS Pharma Animal Health) 2 months before the trial. All horses were fed timothy grass hay (10 $\mathrm{g} / \mathrm{BW} \mathrm{kg} /$ day), and alfalfa hay cubes (6 g/BW $\mathrm{kg} /$ day) at 05:00, 12:00 and 16:30. Barley and pelleted feed were fed to horses, and their daily amounts were changed in accordance with the day's exercise intensity (each amount was about 0.5 to $6 \mathrm{~kg}$ /day). The feeding protocol used in this study referenced previously described recommendations [1]. All experiments were performed in accordance with the guidelines of the University Animal Care and Use Committee at Tokyo University of Agriculture and Technology.

\section{Probiotics}

The probiotic supplement used in this study was a commercially available fermented liquid product (Equine Probiotics Performance; Nanomax Inc.) derived from molasses, malt, oats, corn, rice, barley, alfalfa seeds, rye, millet, linseed, and water. After natural fermentation, the product contained $5.6 \times 10^{8}$ colony-forming units (CFU)/g of L. acidophilus and $2.6 \times 10^{4} \mathrm{CFU} / \mathrm{g}$ of yeast species, including $S$. cerevisiae and $S$. boulardii.

\section{Study design}

A double-blinded crossover study was performed (Fig. 1). The horses were divided into 2 randomized groups: the probiotic-treated group $(n=5)$ and the control group $(n=5)$. When the horses were fed their diets at 16:30, the horses in the probiotic-treated group received $200 \mathrm{ml}$ of the probiotics, including $1.15 \times 10^{11} \mathrm{CFU}$ of L. acidophilus and $5.32 \times 10^{6}$ yeast CFU. The horses in the control group were treated with $200 \mathrm{ml}$ of $0.9 \%$ saline as a placebo. The horses received probiotics or saline daily for 28 days during the first phase of the study. After a washout period of 14 days, the treatment groups were switched for a period of 28 days. The duration of the washout period was determined by reference to a human crossover study [4], and it was confirmed that there was no statistical difference in pretreatment data between the 2 periods. To ensure complete consumption of the probiotics and saline, the horses were fed with a small amount of pelleted feed before feeding of timothy grass hay and alfalfa hay cubes. The horse care staff confirmed that there was no difference in palatability between the probiotics and saline. On each day of the study, staff members who were blind to the protocol graded the clinical conditions of the horses on a five-point scale (Table 1). Each staff member had taken care of each horse for at least 4 months before the trial and defined the normal level of clinical conditions as a score of 3. During the course of study, the same person recorded the score. Appetite was judged by the amount of feed leftover $1 \mathrm{hr}$ after feeding. Blood and fresh fecal samples were collected just before the study (day 0), on day 14 and on day 28. These samples were analyzed by veterinarians.

Blood samples were collected from the jugular vein at 14:00. Fresh fecal samples were obtained at 5:00 before feeding. The fecal samples were put into sterile plastic tubes on ice immediately after defecation and brought to the laboratory. Biochemical analysis was performed immediately on a subset of these samples; the others were preserved at $-20^{\circ} \mathrm{C}$ until further examination. The staff and veterinary physicians were blinded to whether the horses received probiotics or saline.

\section{Blood tests}

The blood samples collected were immediately transferred to EDTA tubes for performance of complete blood count $(\mathrm{CBC})$ analysis and were heparinized for chemical analyses. The $\mathrm{CBC}$ analysis was performed using a Celltac $\alpha$ hematology analyzer (Nihon Kohden, Tokyo, Japan). Hemograms were assessed using blood smear preparations. After separation of plasma from heparinized blood, blood chemical analysis was performed using a DRI-CHEM analyzer (Fujifilm, Tokyo, Japan) to measure the concentration of glucose, blood urea nitrogen, aspartate aminotransferase, alanine aminotransferase, alkaline phosphatase, total bilirubin, total cholesterol, total protein, creatine phosphokinase, sodium ion, potassium ion and chloride ion. 


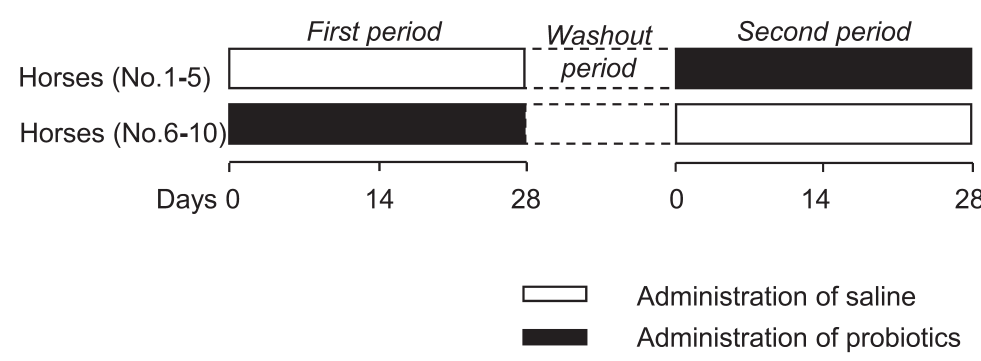

Fig. 1. Study design. A double blind cross-over study was performed. Ten horses were randomly divided into 2 groups. The first phase of treatment lasted 28 days. Five horses (No. 1-5) received probiotics in liquid form; the others (No. 6-10) were treated with saline. After a washout period (14 days), the treatment groups were switched.

Table 1. The criteria for scoring of clinical conditions

\begin{tabular}{ccl}
\hline \multicolumn{1}{c}{ Item } & Score & \multicolumn{1}{c}{ Criteria } \\
\hline Vigor / appetite & 1 & Lost \\
& 2 & Decreased \\
& 3 & Normal \\
& 4 & Increased \\
Fecal condition & 5 & Excessive \\
& 1 & Watery diarrhea / constipation \\
& 2 & Loose stool / scybalum \\
& 3 & Normal \\
& 4 & Superior \\
& 5 & Optimal \\
\hline
\end{tabular}

\section{Biochemical fecal analysis}

After incubation at room temperature for $30 \mathrm{~min}$, fecal $\mathrm{pH}$ was measured using a $\mathrm{pH}$ meter (DKK-TOA Corporation, Tokyo, Japan). Each sample was tested three times, and the average score was recorded. For the carboxylic acid measurements, $3 \mathrm{~g}$ of each fecal sample was transferred into a closed plastic bag together with $500 \mathrm{~m} l$ of air. The bag was incubated at $37^{\circ} \mathrm{C}$ for $30 \mathrm{~min}$, and then the concentration of volatilized gas in the bag was determined using a gas detector tube (Komyo Rikagaku Kogyo, Kanagawa, Japan) [35].

\section{Fecal gas chromatography for the detection of VOCs}

Phenol-d6 (internal standard, 99\%), phenol (>99.0\%), 4-methylphenol (99.2\%), 4-ethylphenol (99\%), indole ( $>99 \%)$ and 3-methylindole (98\%) were purchased from Sigma-Aldrich. Standard solutions of each compound were prepared in methanol 5,000 (Wako) and stored at $4^{\circ} \mathrm{C}$. VOCs were extracted from $1 \mathrm{~g}$ of the fecal sample with methanol, and the concentrations of phenol, 4-methylphenol, 4-ethylphenol, indole and 3-methylindole were measured by gas chromatograph mass spectrometry (GC/MS) as previously reported, with some modifications [17]. The identification and quantification of the compounds were performed by GC/MS (GC, 7890A; MS, 5975C; Agilent Technologies). DB-624 (60 m $\times 0.32 \mathrm{~mm}$, i.d., $1.8 \mu \mathrm{m}$ film, J\&W) capillary columns were used. The column oven temperature was programmed to increase at a rate of $30^{\circ} \mathrm{C} / \mathrm{min}$ from an initial temperature of $75^{\circ} \mathrm{C}$ ( $3 \mathrm{~min}$ hold $)$ to $150^{\circ} \mathrm{C}$, then to increase at a rate of $10^{\circ} \mathrm{C} / \mathrm{min}$ to $200^{\circ} \mathrm{C}$ and finally at a rate of $30^{\circ} \mathrm{C} /$ $\min$ to $240^{\circ} \mathrm{C}$ (7 min hold).

\section{Real-time polymerase chain reaction (PCR) for fecal levels of microbial DNA}

The method of detecting bacterial DNA by using PCR has been developed and improved by many researchers, and its accuracy is high [8]. For quantitative analysis of bacteria, $200 \mathrm{mg}$ of feces were measured and immediately stored at $-20^{\circ} \mathrm{C}$. The bacterial DNA in each sample was extracted into $200 \mu l$ of elution buffer using a QIAamp DNA Stool Mini kit (Qiagen) within a week. The DNA was stored at $-20^{\circ} \mathrm{C}$ prior to analysis according to the manufacturer's instructions. Bacterial DNA was amplified with SYBR Premix Ex Taq II (Takara Bio) in the presence of $0.2 \mu \mathrm{mol} / l$ of each primer for L. acidophilus (5'-CACAATGGACGAAAGTCTGATG-3' and 5'- CGCCACTGGTGTTCTTCCAT-3'), S. cerevisiae (5'-AGGAGTGCGGTTCTTTG-3' and 5'- TACTTACCGAGGCAAGCTACA-3') and E. coli (5'-GCGTTGCGTAAATATGGTTGCCGA-3' and 5'-CGTCACAGGCTTCAATCATGCGTT-3') [2, 3, 16]. The primer for $C$. perfringens was purchased from Takara Bio. The following thermal cycling programs were used: stage $1,50^{\circ} \mathrm{C}$ for 2 min; stage $2,95^{\circ} \mathrm{C}$ for $10 \mathrm{~min}$; stage 3,40 cycles of $95^{\circ} \mathrm{C}$ for $15 \mathrm{sec}$ and $60^{\circ} \mathrm{C}$ for $1 \mathrm{~min}$. Fluorescence intensity was measured in real time during extension steps by using an ABI Prism 7000 Sequence Detector (Applied Biosystems). Relative expression levels of the target gene were calculated by $2^{-\Delta \mathrm{CT}}$. 
A

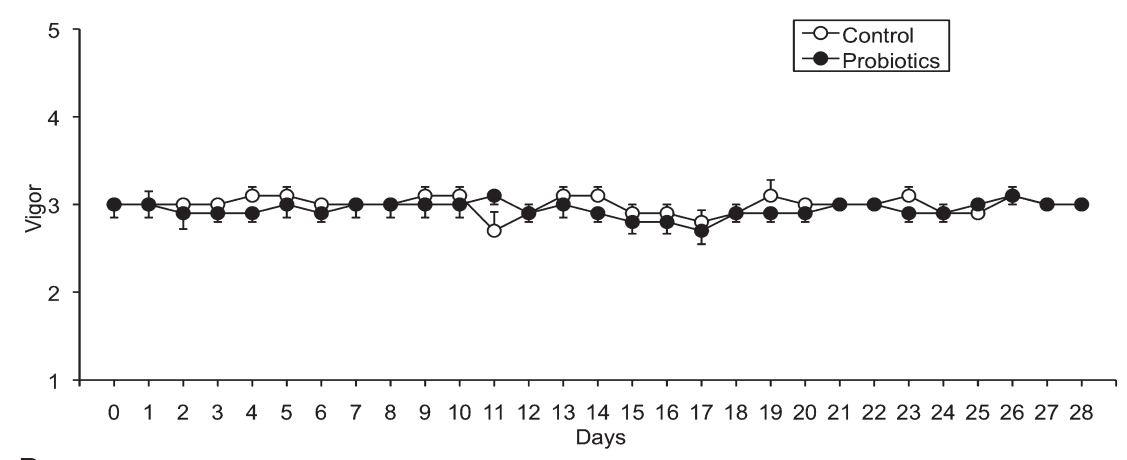

B

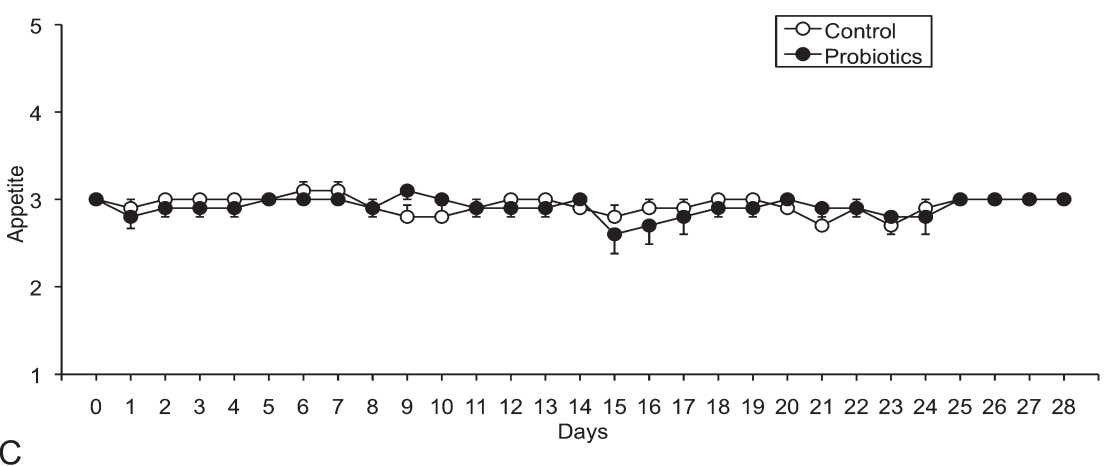

C

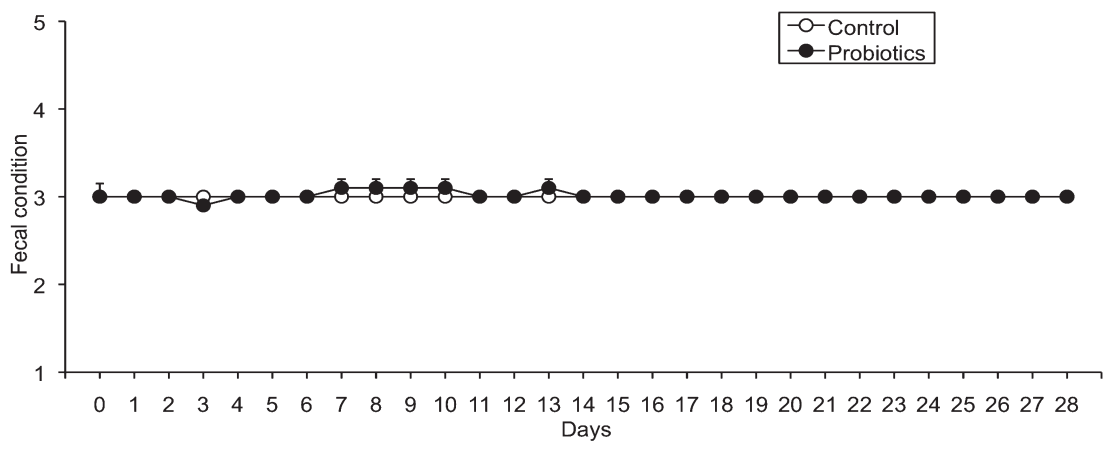

Fig. 2. Clinical conditions. Clinical conditions were scored daily. There were no significant differences between the control group and the probiotics-treated group in terms of vigor (A), fecal quality (B), or appetite (C). No significant change was observed in either group over the course of the study period.

\section{Statistical analysis}

Because no differences between groups were noted at baseline, the first and second phases of each treatment were combined for statistical analysis. The Wilcoxon signed-rank test and Mann-Whitney $U$-test were used for clinical score comparisons. Student's paired or unpaired $t$-tests were used for comparisons of blood test data, fecal $\mathrm{pH}$, carboxylic acid levels, concentrations of VOCs, and levels of bacterial DNA. Statistical significance was determined using Tukey's method as a multiple comparison. $P$ values of $<0.05$ were considered statistically significant.

\section{Results}

Clinical observation and blood tests

All horses in both the control and probiotic-treated groups were clinically healthy before starting the examination. There was no difference between the groups. In both groups, the results of the assessment of clinical conditions (Fig. 2) and blood tests (data not shown) were within the normal ranges at day 0 , and they were stable throughout the study period. There was no significant difference between the groups. 

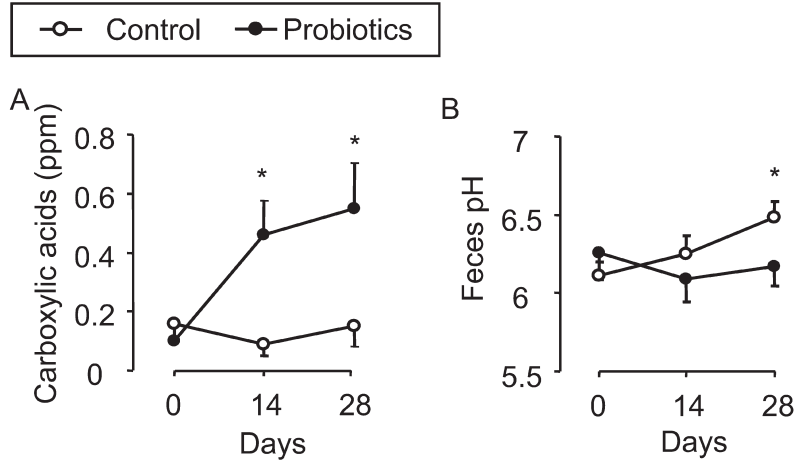

Fig. 3. Chemical analysis of equine feces. Fecal carboxylic acid concentrations were determined with gas-detecting tubes (A). The concentration of volatilized gas was determined. Concentrations increased after treatment with probiotics but not saline. Fecal $\mathrm{pH}$ was measured with a $\mathrm{pH}$ meter (B). Each sample was tested 3 times and the average score was recorded. $* P<0.05$, compared with day 0 .

\section{Chemical analysis of fecal samples}

Administration of probiotics increased the fecal carboxylic acid levels, but administration of saline group did not (Fig. 3A). The feces pH levels showed a slight increase in the control group horses; however, no such change was observed in the probiotic-treated horses (Fig. 3B).

\section{Fecal levels of VOCs}

The concentrations of phenol, 4-methylphenol, 4-ethylphenol, indole and skatole were measured by GC/MS. Probiotic treatment induced a gradual reduction in the levels of phenol and indole, as well as a dramatic decrease in 4-methylphenol levels (Fig. 4A). A significant reduction was obvious in the 4-methylphenol levels of the probiotictreated horses after 28 days when compared with the levels of the control horses (Fig. 4B). In the control group, the levels of all VOCs measured tended to increase throughout the study period.

\section{Real-time PCR for the detection of bacterial DNA in feces}

To confirm the change in bacterial numbers after probiotic treatment, equine fecal levels of bacterial DNA were detected by real-time PCR analysis. The relative amounts of $L$. acidophilus and $S$. cerevisiae increased in the feces of probiotic-treated but not control horses (Fig. 5A and 5B). The relative amounts of $E$. coli and $C$. perfringens were reduced in the feces from the probiotic-treated group as compared with the control group (Fig. 5C and 5D).

\section{Discussion}

This study investigated the effects of consumption of fermented probiotics on adult horses. We demonstrated that oral administration of probiotics for 28 days increased $L$. acidophilus and $S$. cerevisiae levels in the gut, resulting in improved intestinal health.

The relationship between probiotics treatment and low $\mathrm{pH}$ conditions in the intestines has been previously reviewed, and some in vitro studies have demonstrated that probiotic bacteria release carboxylic acids such as lactic acid and acetic acid, and have inhibitory effects on the growth and invasive function of $E$. coli in low pH conditions [18, 20, 23]. For example, oral administration of L.acidophilus decreased the fecal $\mathrm{pH}$ and numbers of Clostridium spp. and Enterococcus faecalis in cats [18]. Although supplementation of $S$. cerevisiae has been reported to prevent acidification of feces and improve microbial fibrolytic activities induced by a high-fiber or high-starch diet in horses $[14,19]$, there is little information regarding the effects of enterobacteria on fecal $\mathrm{pH}$ in horses. In our study, the fecal $\mathrm{pH}$ of the control horses showed a slight increase during the experiment. However, even on day 28 , the feces of the control group was weakly acidic. Therefore, the probiotic microorganisms used in this study might maintain a stable fecal $\mathrm{pH}$ by increasing the production of carboxylic acids. Although DNA levels are not direct evidence of bacterial population numbers, the maintenance of a lower fecal $\mathrm{pH}$ and the elevation in fecal carboxylic acid concentrations suggest increased enteric populations of lactic acid-producing bacteria. An acidic $\mathrm{pH}$ in the intestines of horses is thought to be detrimental due to the acid sensitivity of fiber-degrading bacteria; however, the fecal $\mathrm{pH}$ in the probiotic-treated horses was within a physiological range during the experiment. Therefore, appropriate supplementation of probiotics did not have a negative influence on the gut environment of the horses. It has been reported that the concentration of 4-methylphenol was reduced by administration of probiotics in humans [29]. Moreover, it is known that enteropathogenic bacteria, such as E. coli, produce VOCs. Therefore, the reduction in the amount of 4-methylphenol in the feces of the probiotictreated horses is considered to be a favorable result. Our finding that the relative levels of E. coli and C. perfringens were significantly reduced as a result of probiotic supplementation is notable, since these organisms are pathogenic when toxins are produced. Further studies to examine the effects of probiotics on toxin production by pathogenic bacteria are warranted.

The administration of probiotics had no adverse effects on equine clinical conditions or blood properties. Because the liquid product used in this trial was naturally fermented, it 

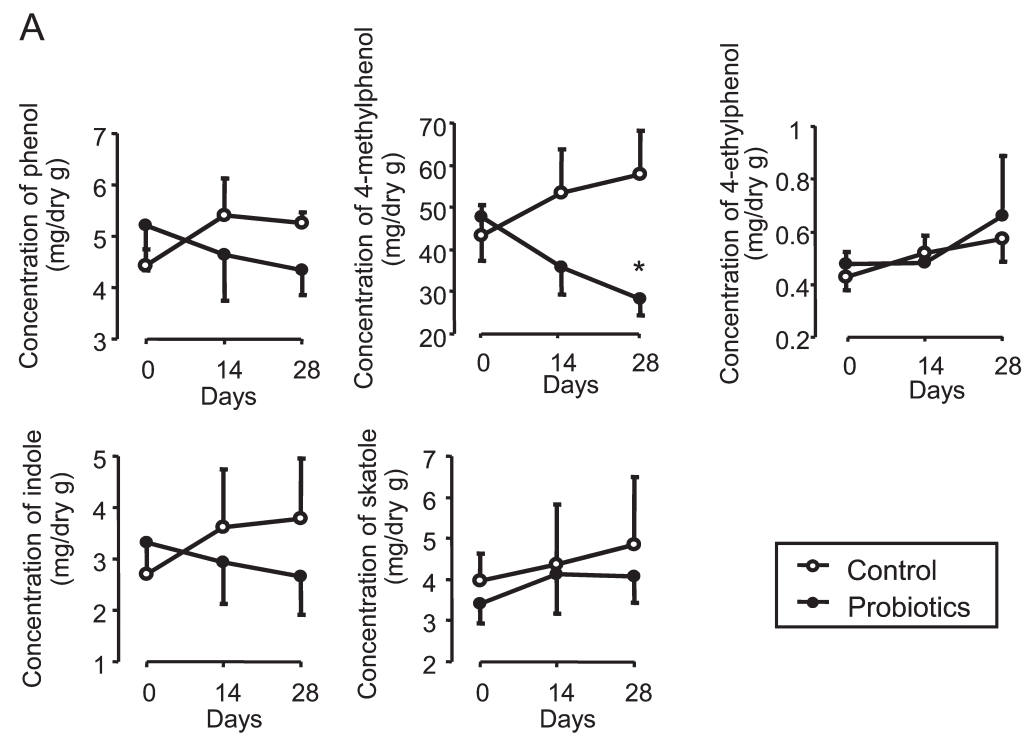

B
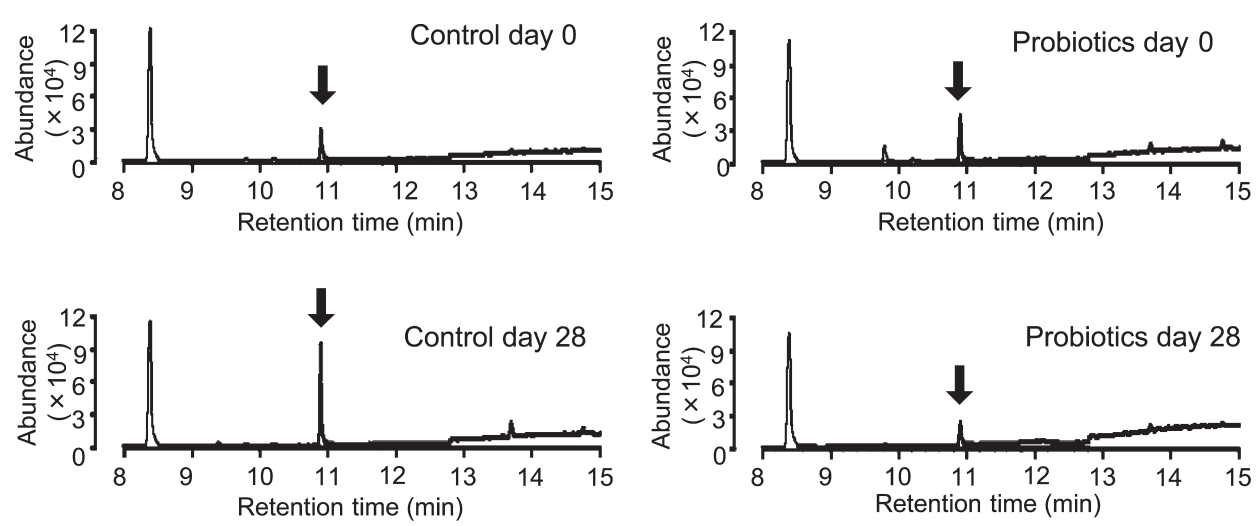

Fig. 4. Levels of VOCs in feces. The concentrations of phenol, 4-methylphenol, 4-ethylphenol, indole, and skatole in $1 \mathrm{~g}$ of equine feces were measured with a gas chromatograph mass spectrometer. The graphs show mean values $\pm \mathrm{SE}$ of each VOC concentration (A). The representative raw data from GC/ MS for detection of 4-methylphenol before and after the 28-day trial are shown (B). Arrows indicate peaks of 4-methylphenol. $* P<0.05$, compared with the control group.

contains not only probiotics but also non-probiotic elements such as prebiotics and biogenics. Prebiotics consisting with short-chain fructo-oligosaccharides have been reported to be effective in stabilizing microbial populations in the equine hindgut [25]. Therefore, it is possible that non-probiotic factors contribute to the favorable effect of the fermented probiotics used in the present study.

In conclusion, the fermented liquid probiotics tested in this study improved the intestinal condition in adult horses without any adverse effects.

\section{Conflict of Interest}

The authors declare that they have no competing financial interests.

\section{Acknowledgment}

We thank all the members of the horse riding club at the Tokyo University of Agriculture and Technology for their great assistance in our experiment. 

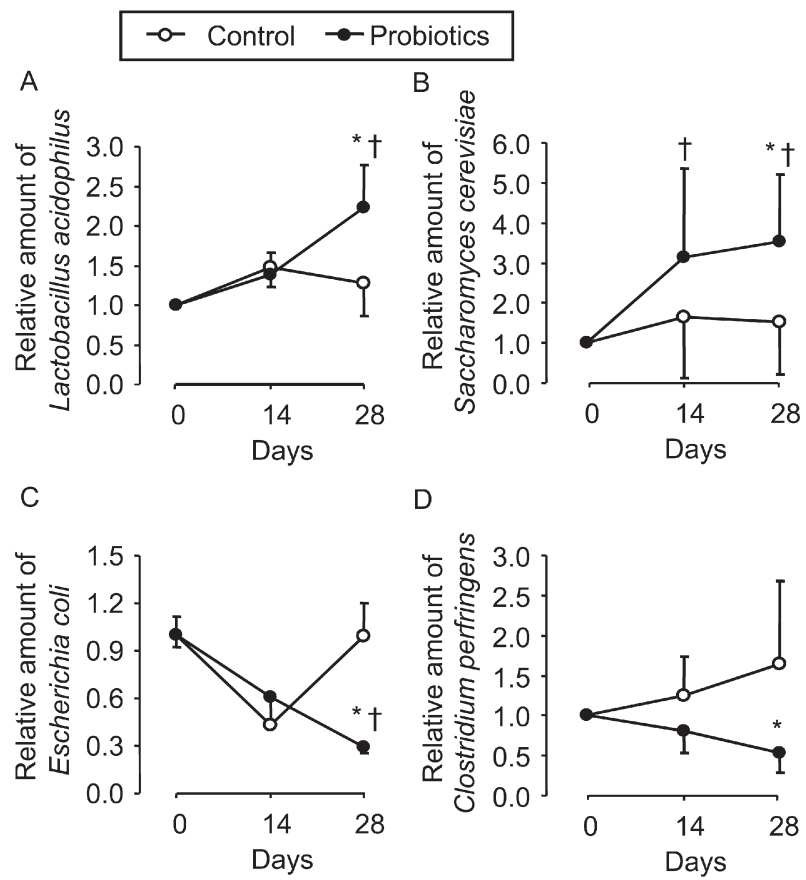

Fig. 5. Real-time PCR for the detection of bacterial DNA in feces. The bacterial DNA extracted from feces was amplified with each primer for L. acidophilus, S. cerevisiae, E. coli, and $C$. perfringens. The relative amounts of L. acidophilus (A) and S. cerevisiae (B) were higher in the feces of probiotic-treated the horses than in that of control horses. The relative amounts of $E$. coli $(\mathrm{C})$ and $C$. perfringens (D) were lower in the feces of probiotic-treated horses than in the feces of control horses. $* P<0.05$, compared with the saline-treated group. $\uparrow P<0.05$, compared with day 0 .

\section{References}

1. Asai, Y. 2012. Feeding System. pp. 167-199. In: Equine Veterinary Medicine, New Ed. Japan Racing Association, Midori-Shobou, Tokyo.

2. Chang, H.W., Nam, Y.D., Sung, Y., Kim, K.H., Roh, S.W., Yoon, J.H., An, K.G., and Bae, J.W. 2007. Quantitative real time PCR assays for the enumeration of Saccharomyces cerevisiae and the Saccharomyces sensu stricto complex in human feces. J. Microbiol. Methods 71: 191-201. [Medline] [CrossRef]

3. Chen, Y.C., Higgins, M.J., Maas, N.A., and Murthy, S.N. 2006. DNA extraction and Escherichia coli quantification of anaerobically digested biosolids using the competitive touchdown PCR method. Water Res. 40: 3037-3044. [Medline] [CrossRef]

4. De Preter, V., Raemen, H., Cloetens, L., Houben, E., Rutgeerts, P., and Verbeke, K. 2008. Effect of dietary intervention with different pre- and probiotics on intestinal bacterial enzyme activities. Eur. J. Clin. Nutr. 62: 225-231. [Medline] [CrossRef]
5. Desrochers, A.M., Dolente, B.A., Roy, M.F., Boston, R., and Carlisle, S. 2005. Efficacy of Saccharomyces boulardii for treatment of horses with acute enterocolitis. J. Am. Vet. Med. Assoc. 227: 954-959. [Medline] [CrossRef]

6. Diab, S.S., Kinde, H., Moore, J., Shahriar, M.F., Odani, J., Anthenill, L., Songer, G., and Uzal, F.A. 2012. Pathology of Clostridium perfringens type $\mathrm{C}$ enterotoxemia in horses. Vet. Pathol. 49: 255-263. [Medline] [CrossRef]

7. Francavilla, R., Lionetti, E., Castellaneta, S., Ciruzzi, F., Indrio, F., Masciale, A., Fontana, C., La Rosa, M.M., Cavallo, L., and Francavilla, A. 2012. Randomised clinical trial: Lactobacillus reuteri DSM 17938 vs. placebo in children with acute diarrhoea-a double-blind study. Aliment. Pharmacol. Ther. 36: 363-369. [Medline] [CrossRef]

8. Fu, C.J., Carter, J.N., Li, Y., Porter, J.H., and Kerley, M.S. 2006. Comparison of agar plate and real-time PCR on enumeration of Lactobacillus, Clostridium perfringens and total anaerobic bacteria in dog faeces. Lett. Appl. Microbiol. 42: 490-494. [Medline] [CrossRef]

9. Gao, X.W., Mubasher, M., Fang, C.Y., Reifer, C., and Miller, L.E. 2010. Dose-response efficacy of a proprietary probiotic formula of Lactobacillus acidophilus CL1285 and Lactobacillus casei LBC80R for antibiotic-associated diarrhea and Clostridium difficile-associated diarrhea prophylaxis in adult patients. Am. J. Gastroenterol. 105: 1636-1641. [Medline] [CrossRef]

10. Glade, M.J. 1991. Dietary yeast culture supplementation of mares during late gestation and early lactation. Effects on dietary nutrient digestibilities and fecal nitrogen partitioning. J. Equine Vet. Sci. 11: 10-16. [CrossRef]

11. Holland, R.E., Grimes, S.D., Walker, R.D., and Wilson, R.A. 1996. Experimental inoculation of foals and pigs with an enterotoxigenic E. coli isolated from a foal. Vet. Microbiol. 52: 249-257. [Medline] [CrossRef]

12. Janke, B.H., Francis, D.H., Collins, J.E., Libal, M.C., Zeman, D.H., and Johnson, D.D. 1989. Attaching and effacing Escherichia coli infections in calves, pigs, lambs, and dogs. J. Vet. Diagn. Invest. 1: 6-11. [Medline] [CrossRef]

13. Jouany, J.P., Gobert, J., Medina, B., Bertin, G., and Julliand, V. 2008. Effect of live yeast culture supplementation on apparent digestibility and rate of passage in horses fed a high-fiber or high-starch diet. J. Anim. Sci. 86: 339-347. [Medline] [CrossRef]

14. Jouany, J.P., Medina, B., Bertin, G., and Julliand, V. 2009. Effect of live yeast culture supplementation on hindgut microbial communities and their polysaccharidase and glycoside hydrolase activities in horses fed a high-fiber or high-starch diet. J. Anim. Sci. 87: 2844-2852. [Medline] [CrossRef]

15. Kim, L.M., Morley, P.S., Traub-Dargatz, J.L., Salman, M.D., and Gentry-Weeks, C. 2001. Factors associated with Salmonella shedding among equine colic patients at a veterinary teaching hospital. J. Am. Vet. Med. Assoc. 218: 740-748. [Medline] [CrossRef] 
16. Kramer, M., Obermajer, N., Bogovic Matijasić, B., Rogelj, I., and Kmetec, V. 2009. Quantification of live and dead probiotic bacteria in lyophilised product by real-time PCR and by flow cytometry. Appl. Microbiol. Biotechnol. 84: 1137-1147. [Medline] [CrossRef]

17. Larreta, J., Vallejo, A., Bilbao, U., Alonso, A., Arana, G., and Zuloaga, O. 2006. Experimental design to optimise the analysis of organic volatile compounds in cow slurry by headspace solid-phase microextraction-gas chromatography-mass spectrometry. J. Chromatogr. A. 1136: 1-9. [Medline] [CrossRef]

18. Marshall-Jones, Z.V., Baillon, M.L.A., Croft, J.M., and Butterwick, R.F. 2006. Effects of Lactobacillus acidophilus DSM13241 as a probiotic in healthy adult cats. Am. J. Vet. Res. 67: 1005-1012. [Medline] [CrossRef]

19. Medina, B., Girard, I.D., Jacotot, E., and Julliand, V. 2002. Effect of a preparation of Saccharomyces cerevisiae on microbial profiles and fermentation patterns in the large intestine of horses fed a high fiber or a high starch diet. $J$. Anim. Sci. 80: 2600-2609. [Medline]

20. Miyazaki, Y., Kamiya, S., Hanawa, T., Fukuda, M., Kawakami, H., Takahashi, H., and Yokota, H. 2010. Effect of probiotic bacterial strains of Lactobacillus, Bifidobacterium, and Enterococcus on enteroaggregative Escherichia coli.J. Infect. Chemother. 16: 10-18. [Medline] [CrossRef]

21. Ogata, T., Kingaku, M., Yaeshima, T., Teraguchi, S., Fukuwatari, Y., Ishibashi, N., Hayasawa, H., Fujisawa, T., and Iino, H. 1999. Effect of Bifidobacterium longum BB536 yogurt administration on the intestinal environment of healthy adults. Microb. Ecol. Health Dis. 11: 41-46. [CrossRef]

22. Parraga, M.E., Spier, S.J., Thurmond, M., and Hirsh, D. 1997. A clinical trial of probiotic administration for prevention of Salmonella shedding in the postoperative period in horses with colic. J. Vet. Intern. Med. 11: 36-41. [Medline] [CrossRef]

23. Parvez, S., Malik, K.A., Ah Kang, S., and Kim, H.Y. 2006. Probiotics and their fermented food products are beneficial for health. J. Appl. Microbiol. 100: 1171-1185. [Medline] [CrossRef]

24. Patterson, J.A., and Burkholder, K.M. 2003. Application of prebiotics and probiotics in poultry production. Poult. Sci. 82: 627-631. [Medline] [CrossRef]

25. Respondek, F., Goachet, A.G., and Julliand, V. 2008. Effects of dietary short-chain fructooligosaccharides on the intestinal microflora of horses subjected to a sudden change in diet. J. Anim. Sci. 86: 316-323. [Medline] [CrossRef]

26. Reid, G., Jass, J., Sebulsky, M.T., and McCormick, J.K. 2003. Potential uses of probiotics in clinical practice. Clin. Microbiol. Rev. 16: 658-672. [Medline] [CrossRef]

27. Roessler, A., Forssten, S.D., Glei, M., Ouwehand, A.C., and Jahreis, G. 2012. The effect of probiotics on faecal microbiota and genotoxic activity of faecal water in patients with atopic dermatitis: a randomized, placebo-controlled study. Clin. Nutr. 31: 22-29. [Medline] [CrossRef]

28. Sazawal, S., Hiremath, G., Dhingra, U., Malik, P., Deb, S., and Black, R.E. 2006. Efficacy of probiotics in prevention of acute diarrhoea: a meta-analysis of masked, randomised, placebo-controlled trials. Lancet Infect. Dis. 6: 374-382. [Medline] [CrossRef]

29. Suzuki, H., Watabe, J., Takeuchi, H., Tadano, Y., Matsuda, S., and Murata, K. 2004. Effect of Bacillus subtilis C-3102 intakes on the composition and metabolic activity of fecal microflora of humans. J. Intestinal. Microbiol. 18: 93-99.

30. Swyers, K.L., Burk, A.O., Hartsock, T.G., Ungerfeld, E.M., and Shelton, J.L. 2008. Effects of direct-fed microbial supplementation on digestibility and fermentation endproducts in horses fed low- and high-starch concentrates. J. Anim. Sci. 86: 2596-2608. [Medline] [CrossRef]

31. Traub-Dargatz, J.L., Salman, M.D., and Voss, J.L. 1991. Medical problems of adult horses, as ranked by equine practitioners. J. Am. Vet. Med. Assoc. 198: 1745-1747. [Medline]

32. van Duijkeren, E., Sloet van Oldruitenborgh-Oosterbaan, M.M., Breukink, H.J., Vulto, A.G., and van Miert, A.S. 1996. A survey of horses with acute diarrhoea: diagnosis, assessment of the prognosis, and comparison of two antibiotic therapies. Vet. Q. 18: 153-156. [Medline] [CrossRef]

33. Weese, J.S., Anderson, M.E., Lowe, A., Penno, R., da Costa, T.M., Button, L., and Goth, K.C. 2004. Screening of the equine intestinal microflora for potential probiotic organisms. Equine Vet. J. 36: 351-355. [Medline] [CrossRef]

34. Weese, J.S., and Rousseau, J. 2005. Evaluation of Lactobacillus pentosus WE7 for prevention of diarrhea in neonatal foals. J. Am. Vet. Med. Assoc. 226: 2031-2034. [Medline] [CrossRef]

35. Yamakoshi, J., Tokutake, S., Kikuchi, M., Kubota, Y., Konishi, H., and Mitsuoka, T. 2001. Effect of proanthocyanidinrich extract from grape seeds on human fecal flora and fecal odor. Microb. Ecol. Health Dis. 13: 25-31. [CrossRef] 